University of Nebraska - Lincoln

DigitalCommons@University of Nebraska - Lincoln

USDA National Wildlife Research Center - Staff Publications
U.S. Department of Agriculture: Animal and Plant Health Inspection Service

2009

\title{
Strawberry-Flavored Baits for Pharmaceutical Delivery to Feral Swine
}

Tyler A. Campbell

USDA-APHIS-Wildlife Services, tcampbell@eastfoundation.net

David B. Long

USDA-APHIS-Wildlife Services

Follow this and additional works at: https://digitalcommons.unl.edu/icwdm_usdanwrc

Part of the Environmental Sciences Commons

Campbell, Tyler A. and Long, David B., "Strawberry-Flavored Baits for Pharmaceutical Delivery to Feral Swine" (2009). USDA National Wildlife Research Center - Staff Publications. 887.

https://digitalcommons.unl.edu/icwdm_usdanwrc/887

This Article is brought to you for free and open access by the U.S. Department of Agriculture: Animal and Plant Health Inspection Service at DigitalCommons@University of Nebraska - Lincoln. It has been accepted for inclusion in USDA National Wildlife Research Center - Staff Publications by an authorized administrator of DigitalCommons@University of Nebraska - Lincoln. 


\title{
Strawberry-Flavored Baits for Pharmaceutical Delivery to Feral Swine
}

\author{
TYLER A. CAMPBELL, ${ }^{1}$ United States Department of Agriculture, Animal and Plant Health Inspection Service, Wildlife Services, National Wildlife \\ Research Center, Texas AEM University-Kingsville, Kingsville, TX 78363, USA \\ DAVID B. LONG, United States Department of Agriculture, Animal and Plant Health Inspection Service, Wildlife Services, National Wildlife Research \\ Center, Texas AE'M University-Kingsville, Kingsville, TX 78363, USA
}

\begin{abstract}
More effective methods to control feral swine (Sus scrofa) damage are needed. We evaluated 8 oral delivery systems designed to deliver pharmaceuticals to feral swine on 2 properties in southern Texas, USA. We used modified PIGOUT ${ }^{\circledR}$ feral pig bait (Animal Control Technologies Australia P/L, Somerton, Victoria, Australia) throughout our trials to compare species-specific visitation and removal rates. Given our consistent finding of high nontarget removal of baits intended for feral swine, we question whether a swine-specific oral delivery system exists for this region. (JOURNAL OF WILDLIFE MANAGEMENT 73(4):615-619; 2009)
\end{abstract}

DOI: $10.2193 / 2008-326$

KEY WORDS baits, FeralMone, feral swine, oral delivery system, pharmaceutical, PIGOUT, strawberry, Sus scrofa.

Given their recent range expansion and current distribution in the United States and abroad, feral swine (Sus scrofa) are coming increasingly into conflict with humans, agricultural and natural resources, and other wildlife species (Frederick 1998, Waithman et al. 1999, Seward et al. 2004). The goal of wildlife damage management is to increase the net value of wildlife for society by minimizing negative values of wildlife (Conover 2002). As such, the goal of feral swine damage management is to reduce damage caused by the swine, thereby increasing their net value to society. However, feral swine are exotic in the United States and are characterized by invasive behavior across much of their global distribution, where they commonly reach unnatural population levels because of the absence of limiting factors, such as predators. In fact, many would argue that their presence on foreign soils at any level is unnatural and that swift and decisive management actions are needed upon their discovery (Simberloff 2003). In these and other scenarios, damage caused by feral swine is often great.

Current control methods have not been universally successful at controlling feral swine damage, as evidenced by the precipitous increase in abundance and distribution of feral swine and subsequent rise in human conflicts (Dickson et al. 2001, Adams et al. 2006). More effective methods to control feral swine damage or modifications to existing methods are needed (Sweeney et al. 2003). Few studies have examined baits as oral delivery systems of pharmaceuticals (e.g., vaccines or toxicants) to feral swine in the United States. From an island population in Georgia, Fletcher et al. (1990) concluded that oral vaccine delivery to feral swine was feasible and Kavanaugh and Linhart (2000) determined baits could be used to administer pharmaceuticals orally to feral swine. In southern Texas, USA, researchers found high removal (Campbell and Long 2007) and consumption (Campbell et al. 2006) of both fish-flavored and vegetable-flavored PIGOUT ${ }^{\circledR}$ feral pig bait (Animal Control

${ }^{1}$ E-mail: tyler.a.campbell@aphis.usda.gov
Technologies Australia P/L, Somerton, Victoria, Australia). However, removal and consumption was also great for nontarget animals (Campbell et al. 2006, Campbell and Long 2007), a discovery inconsistent with findings for PIGOUT baits evaluated in Australia (Cowled et al. 2006a, b). Campbell and Long (2008) subsequently determined that a strawberry-flavored feed additive (Strawberry Aroma; QualiTech Incorporated, Chaska, MN) may be a swinespecific attractant that could be incorporated into an oral delivery system for pharmaceutical delivery in the United States because of its swine-specific characteristics.

Our objective was to evaluate 8 oral delivery systems designed to deliver pharmaceuticals to feral swine on 2 properties in southern Texas. We hypothesized that 1) baits with strawberry-flavored feed additive would be specific to feral swine, based on previous findings (Campbell and Long 2008); 2) baits with FeralMone ${ }^{\circledR}$ attractant (Pestat; Proprietary Limited Company, Bruce, Australian Capital Territory, Australia), an aerosolized formulation of synthetic fermented egg, would display high feral swine removal, following findings for carnivores from Australia (Hunt et al. 2007); and 3) buried baits would be more specific to feral swine because of the greater below-ground foraging abilities of feral swine compared to nontarget animals.

\section{STUDY AREA}

We conducted our trials in mixed-shrub rangelands in Kleberg and San Patricio counties, Texas, USA. Both properties were dominated by huisache (Acacia farnesiana) and honey mesquite (Prosopis glandulosa). We conducted trial 1 on a 3,035-ha portion of the Santa Gertrudis Division of the King Ranch $\left(27^{\circ} 29^{\prime} \mathrm{N}, 97^{\circ} 54^{\prime} \mathrm{W}\right)$ in Kleberg County, which received an average of $67 \mathrm{~cm}$ of rainfall annually. We conducted trial 2 on the 3,157-ha Rob and Bessie Welder Wildlife Refuge $\left(28^{\circ} 06^{\prime} \mathrm{N}, 97^{\circ} 22^{\prime} \mathrm{W}\right)$ in San Patricio County, which received an average of $79 \mathrm{~cm}$ of rainfall annually. Potential nontarget mammalian wildlife that occurred within the study sites were collared peccaries 
(Pecari tajacu), raccoons (Procyon lotor), striped skunks (Mephitis mephitis), opossums (Didelphis virginiana), 9banded armadillos (Dasypus novemcinctus), badgers (Taxidea taxus), coyotes (Canis latrans), bobcats (Lynx rufus), eastern cottontail rabbits (Sylvilagus floridanus), black-tailed jackrabbits (Lepus californicus), Southern Plains woodrats (Neotoma micropus), hispid cotton rats (Sigmodon hispidus), and white-tailed deer (Odocoileus virginianus).

\section{METHODS}

We used PIGOUT feral pig bait throughout our trials. Our baits were grain-based, moist, cylindrical in shape, and approximately $9 \times 5 \mathrm{~cm}$; they weighed $250 \mathrm{~g}$. We conducted our initial trial (i.e., trial 1) from 30 October 2007 to 3 January 2008 using 5 treatments of PIGOUT baits. Treatments consisted of 1) fish-flavored baits, 2) vegetable-flavored baits, 3) vegetable-flavored baits plus (the above-mentioned) strawberry-flavored feed additive, applied to baits by emersion for $>1$ week, 4) fish-flavored baits plus FeralMone attractant, applied to vegetation between $15 \mathrm{~cm}$ and $20 \mathrm{~cm}$ from baits at time of deployment following the label, and 5) vegetable-flavored baits plus FeralMone, applied as described above.

We hand-placed 60 baits from each of the 5 treatments (i.e., 300 baits) between 0800 hours and 1400 hours. We used roads as transects, placing baits at 200-m intervals. We randomly assigned treatment placement order and maintained this order throughout the trial (i.e., like baits were 1,000 $\mathrm{m}$ apart throughout each trial). We distributed baits throughout the study area between $5 \mathrm{~m}$ and $50 \mathrm{~m}$ from road edges. For each bait we randomly assigned roadside orientation (i.e., right or left side) by flipping a coin. We monitored baits with motion-sensing digital photography (Silent Image; Reconyx, LaCrosse, WI) for $\leq 4$ nights. We placed camera systems $3 \mathrm{~m}$ from baits and programmed systems to "high sensitivity" to capture digital images every 2 seconds for 10 seconds (i.e., 5 actuations) at a 2 -minute trip interval.

We revisited baits and checked camera systems daily from 0800 hours to 1400 hours recording presence or absence of bait or bait condition or to conduct site maintenance (e.g., replace damaged baits). Once baits from all 5 associated treatments were removed or 4 nights had passed, we moved camera systems to their next position on the transect.

We conducted our subsequent trial (i.e., trial 2) from 28 January to 26 April 2008 using 6 treatments of PIGOUT baits. Treatments consisted of 1) fish-flavored baits, 2) vegetable-flavored baits, 3) vegetable-flavored baits plus strawberry feed additive, applied to baits through emersion as described above, 4) fish-flavored baits loosely buried to a depth of approximately $10 \mathrm{~cm}, 5)$ vegetable-flavored baits loosely buried to a depth of approximately $10 \mathrm{~cm}$, and 6) vegetable-flavored baits plus strawberry feed additive loosely buried to a depth of approximately $10 \mathrm{~cm}$. We hand-placed 60 baits from each of the 6 treatments (i.e., 360 baits) between 0800 hours and 1400 hours. We deployed, monitored, and checked baits as described for trial 1 .
We determined species-specific visitation and removal rates of baits through examination of photographs. We defined visitation by species as the total number of individuals that had stopped to investigate (i.e., interest or visual observation) within $1 \mathrm{~m}$ of baits prior to and not including removal. We recorded photographic data into 1 of 4 removal categories: definitely removed by species (i.e., photographs in which the bait is in the mouth of an animal or a series of photographs $10 \mathrm{sec}$ apart in which we only observed the species of record and the bait was found to be removed); likely removed by species (i.e., a series of photographs $\leq 30 \mathrm{~min}$ apart in which we observed only the species of record and the bait was removed); removed by unknown species; and not removed. We considered baits in the definitely and likely categories as removed for our analysis. We report descriptive statistics pertaining to species-specific visitation and removal by trial. We compared removal rates (standardized for visitation, following Kavanaugh and Linhart 2000) among treatments for species with $\geq 30$ cumulative visits using the chi-square statistic with Yates correction (Dowdy and Weardon 1991).

\section{RESULTS}

We found cumulative bait-removal rates (based on presence or absence) for the first through fifth treatments of trial 1 after 4 nights were $90 \%, 97 \%, 78 \%, 90 \%$, and $100 \%$, respectively. We obtained 237,485 digital images of sites where we deployed baits, which allowed us to determine species-specific visitation and removal rates of 231 of 300 baits (Table 1). Overall (5 treatments combined), we found bait-removal rates of $26 \%$ by collared peccaries, $19 \%$ by rodents, $16 \%$ by white-tailed deer, $13 \%$ by cattle, $11 \%$ by feral swine, $9 \%$ by raccoons, $3 \%$ by coyotes, $2 \%$ by striped skunks, and $2 \%$ by opossums. Additionally, we observed eastern cottontail rabbits, bobcats, and wild turkeys (Meleagris gallopavo) visiting baits.

White-tailed deer bait-removal rates differed among treatments $\left(\chi_{4}^{2}=30.62, P<0.001\right)$, with vegetableflavored baits being removed at a greater rate $(28 \%)$ than expected. Collared peccary bait-removal rates ranged from $30 \%$ for strawberry-flavored baits to $60 \%$ for vegetableflavored baits plus FeralMone and did not vary among treatments $\left(\chi_{4}^{2}=15.43, P>0.001\right)$. Rodent bait-removal rates differed among treatments $\left(\chi_{4}^{2}=43.07, P<0.001\right)$ with strawberry-flavored baits removed at a greater rate $(100 \%)$ than expected. Cattle bait-removal rates varied among treatments $\left(\chi_{4}^{2}=40.26, P<0.001\right)$ with fishflavored baits removed at a lesser rate $(14 \%)$ than expected. Feral swine bait-removal rates differed among treatments $\left(\chi_{4}^{2}=63.07, P<0.001\right)$ with fish-flavored and vegetableflavored plus FeralMone baits removed at a greater rate (both 100\%) and fish-flavored plus FeralMone baits removed at a lesser rate $(30 \%)$ than expected. Raccoon bait-removal rates differed among treatments $\left(\chi_{4}^{2}=57.03\right.$, $P<0.001)$ with fish-flavored baits removed at a greater rate $(64 \%)$ and strawberry-flavored baits removed at a lesser rate $(0 \%)$ than expected. Coyote bait-removal rates varied 
Table 1. Number of baits removed per confirmed animal visit (before and including removal) for baits treated with various attractants, monitored with motion-sensing photography ( $n=60 /$ treatment), and distributed from 30 October 2007 to 7 January 2008 in Kleberg County, Texas, USA.

\begin{tabular}{|c|c|c|c|c|c|c|c|c|c|c|c|c|c|c|c|}
\hline \multirow[b]{3}{*}{ Species } & \multicolumn{15}{|c|}{ Treatment } \\
\hline & \multicolumn{3}{|c|}{ Fish } & \multicolumn{3}{|c|}{ Vegetable } & \multicolumn{3}{|c|}{ Strawberry } & \multicolumn{3}{|c|}{ Fish + FeralMone $^{\mathrm{a}}$} & \multicolumn{3}{|c|}{ Vegetable + FeralMone } \\
\hline & Removed & Visit & $\%$ & Removed & Visit & $\%$ & Removed & Visit & $\%$ & Removed & Visit & $\%$ & Removed & Visit & $\%$ \\
\hline White-tailed deer & 2 & 43 & 5 & 15 & 53 & 28 & 2 & 30 & 7 & 3 & 26 & 12 & 14 & 56 & 25 \\
\hline Collared peccary & 13 & 36 & 36 & 14 & 29 & 48 & 10 & 33 & 30 & 7 & 22 & 32 & 15 & 25 & 60 \\
\hline Rodent & 12 & 26 & 46 & 7 & 15 & 47 & 11 & 11 & 100 & 7 & 12 & 58 & 7 & 19 & 37 \\
\hline Cattle & 2 & 14 & 14 & 7 & 12 & 58 & 6 & 16 & 38 & 6 & 19 & 32 & 9 & 14 & 64 \\
\hline Feral swine & 5 & 5 & 100 & 5 & 11 & 45 & 6 & 11 & 55 & 6 & 20 & 30 & 4 & 4 & 100 \\
\hline Raccoon & 7 & 11 & 64 & 3 & 7 & 43 & 0 & 7 & 0 & 7 & 15 & 47 & 4 & 10 & 40 \\
\hline Coyote & 2 & 3 & 67 & 2 & 4 & 50 & 2 & 10 & 20 & 0 & 8 & 0 & 0 & 5 & 0 \\
\hline Opossum & 1 & 2 & 50 & 0 & 1 & 0 & 1 & 3 & 33 & 1 & 5 & 20 & 1 & 7 & 14 \\
\hline Striped skunk & 1 & 2 & 50 & 0 & 3 & 0 & 0 & 3 & 0 & 4 & 5 & 80 & 0 & 4 & 0 \\
\hline Cottontail rabbit & 0 & 3 & 0 & 0 & 2 & 0 & 0 & 0 & 0 & 0 & 1 & 0 & 0 & 3 & 0 \\
\hline Bobcat & 0 & 0 & 0 & 0 & 0 & 0 & 0 & 0 & 0 & 0 & 3 & 0 & 0 & 1 & 0 \\
\hline Wild turkey & 0 & 1 & 0 & 0 & 0 & 0 & 0 & 2 & 0 & 0 & 0 & 0 & 0 & 0 & 0 \\
\hline
\end{tabular}

${ }^{a}$ FeralMone attractant, Pestat; Proprietary Limited Company, Bruce, Australian Capital Territory, Australia.

among treatments $\left(\chi_{4}^{2}=132.08, P<0.001\right)$ with fishflavored baits removed at a greater rate $(67 \%)$ and fishflavored plus FeralMone and vegetable-flavored plus FeralMone removed at a lesser rate (both $0 \%$ ) than expected.

We found cumulative bait-removal rates (based on presence or absence) for the first through sixth treatments of trial 2 after 4 nights were $68 \%, 75 \%, 70 \%, 60 \%, 62 \%$, and $72 \%$, respectively. We obtained 385,151 digital images of sites where we deployed baits, which allowed us to determine species-specific visitation and removal rates of 217 of 360 baits (Table 2). Overall (6 treatments combined), we found bait-removal rates of $73 \%$ by raccoons, $23 \%$ by feral swine, $2 \%$ by coyotes, and the remaining $2 \%$ by opossums, white-tailed deer, collared peccary, and rodents. Additionally, we observed armadillos, cattle, and turkey vultures (Cathartes aura) visiting baits.

Raccoon bait-removal rates differed among treatments $\left(\chi^{2}{ }_{5}=38.44, P<0.001\right)$ with fish-flavored baits removed at a greater rate $(58 \%)$ than expected. Feral swine baitremoval rates did not differ among treatments $\left(\chi^{2}{ }_{5}=10.38\right.$, $P>0.001)$ with bait-removal rates ranging from $42 \%$ for fish-flavored baits to $71 \%$ for strawberry-flavored baits. White-tailed deer bait-removal rates differed among treatments $\left(\chi_{5}^{2}=28.71, P<0.001\right)$ with vegetable-flavored baits removed at a greater rate $(6 \%)$ than expected.

\section{DISCUSSION}

Our cumulative bait-removal rates for trial 1 and trial 2 suggest that PIGOUT baits were used heavily by mammalian wildlife, including feral swine. These findings are in agreement with previous studies from southern Texas (Campbell et al. 2006, Campbell and Long 2007) and Australia (Cowled et al. 2006a, b). Similar to Campbell and Long (2007), we found overall (all 5 treatments combined) cattle bait-removal rates of $13 \%$ during trial 1 . Previously, we attributed comparatively high removal rates by cattle (17-29\%) to drought conditions limiting forage availability (Campbell and Long 2007). However, the Palmer Drought
Index (Palmer 1968) from October to January 2008 (i.e., during trial 1) indicated extremely moist to mid-range conditions and from January to April 2008 (i.e., during trial $2,0 \%$ removal by cattle) the index indicated mid-range conditions (National Climatic Data Center 2008), thereby providing evidence in contrast to our hypothesis. An alternative explanation may be that some breeds of cattle find PIGOUT baits to be more palatable than do other breeds (S. J. Lapidge, Invasive Animals Cooperative Research Centre, unpublished data). For example, the Santa Cruz breed was stocked in Campbell and Long (2007) and during our trial 1 , whereas the Brahman breed was stocked during our trial 2.

Our first hypothesis was that baits with strawberryflavored feed additive would be specific to feral swine. During trial 1 we found cumulative bait-removal rates for strawberry-flavored baits to generally be lower $(78 \%)$ than for other treatments $(90-100 \%)$ and also that rodents preferred strawberry baits $(100 \%$ removal) and raccoons avoided strawberry baits ( $0 \%$ removal). During trial 2 we determined no preference or avoidance behaviors relative to the strawberry baits by mammalian wildlife. These collective findings were counter to our hypothesis. Campbell and Long (2008) found no visitation to strawberry scent stations by raccoons or collared peccaries, the primary nontarget animals removing PIGOUT baits in southern Texas (Campbell et al. 2006), but here we recorded visitation and removal by these species when strawberry flavoring was incorporated into PIGOUT baits. Interestingly, during trial 2 , raccoons visited both surface-deployed (142 visits) and buried (129 visits) strawberry baits at a high rate, perhaps indicating raccoons' reluctant consumption of strawberry baits.

Our second hypothesis was that baits with FeralMone attractant would display high feral swine removal. During trial 1 we found cumulative bait-removal rates for baits containing FeralMone to be high (90\% and 100\%). Additionally, we determined that feral swine preferred 
Table 2. Number of baits removed per confirmed animal visit (before and including removal) for baits treated with various attractants, monitored with motion-sensing photography ( $n=60 /$ treatment), and distributed from 28 January 2008 to 26 April 2008 in San Patricio County, Texas, USA.

\begin{tabular}{|c|c|c|c|c|c|c|c|c|c|c|c|c|c|c|c|c|c|c|}
\hline \multirow[b]{3}{*}{ Species } & \multicolumn{18}{|c|}{ Treatment } \\
\hline & \multicolumn{3}{|c|}{ Fish } & \multicolumn{3}{|c|}{ Vegetable } & \multicolumn{3}{|c|}{ Strawberry } & \multicolumn{3}{|c|}{ Fish buried } & \multicolumn{3}{|c|}{ Vegetable buried } & \multicolumn{3}{|c|}{ Strawberry buried } \\
\hline & Removed & Visit & $\%$ & Removed & Visit & $\%$ & Removed & Visit & $\%$ & Removed & Visit & $\%$ & Removed & Visit & $\%$ & Removed & Visit & $\%$ \\
\hline Raccoon & 34 & 59 & 58 & 28 & 89 & 31 & 21 & 142 & 15 & 26 & 89 & 29 & 27 & 80 & 34 & 22 & 129 & 17 \\
\hline Feral swine & 5 & 12 & 42 & 10 & 16 & 63 & 15 & 21 & 71 & 1 & 2 & 50 & 4 & 6 & 67 & 14 & 24 & 58 \\
\hline White-tailed deer & 0 & 3 & 0 & 1 & 17 & 6 & 0 & 14 & 0 & 0 & 3 & 0 & 0 & 1 & 0 & 0 & 4 & 0 \\
\hline Coyote & 2 & 3 & 67 & 1 & 3 & 33 & 0 & 3 & 0 & 2 & 3 & 67 & 0 & 1 & 0 & 0 & 3 & 0 \\
\hline Opossum & 0 & 0 & 0 & 1 & 4 & 25 & 1 & 4 & 25 & 0 & 0 & 0 & 0 & 0 & 0 & 0 & 6 & 0 \\
\hline Collared peccary & 0 & 2 & 0 & 0 & 2 & 0 & 0 & 0 & 0 & 0 & 3 & 0 & 1 & 2 & 50 & 0 & 2 & 0 \\
\hline Armadillo & 0 & 1 & 0 & 0 & 0 & 0 & 0 & 0 & 0 & 0 & 2 & 0 & 0 & 1 & 0 & 0 & 2 & 0 \\
\hline Cattle & 0 & 0 & 0 & 0 & 1 & 0 & 0 & 3 & 0 & 0 & 0 & 0 & 0 & 0 & 0 & 0 & 1 & 0 \\
\hline Rodent & 0 & 0 & 0 & 1 & 1 & 100 & 0 & 1 & 0 & 0 & 0 & 0 & 0 & 0 & 0 & 0 & 0 & 0 \\
\hline Turkey vulture & 0 & 1 & 0 & 0 & 0 & 0 & 0 & 0 & 0 & 0 & 0 & 0 & 0 & 0 & 0 & 0 & 0 & 0 \\
\hline
\end{tabular}

vegetable-flavored plus FeralMone baits (100\% removal); however, white-tailed deer, collared peccaries, rodents, cattle, raccoons, and opossums also removed this bait type on $14-64 \%$ of visits, suggesting that this bait type was not specific to feral swine. Interestingly, coyotes avoided removing bait types with FeralMone attractant added, which was surprising in that FeralMone is based on a proprietary formulation of synthetic fermented egg (Bullard et al. 1978) found to increase visitation and bait removal by red foxes (Vulpes vulpes) and wild dogs in Australia (Hunt et al. 2007). Also surprising was our observation of visitation and removal of baits with FeralMone attractant by whitetailed deer because synthetic fermented egg has previously been determined to repel deer (Bullard et al. 1978).

Our third hypothesis was that buried baits would be more specific to feral swine because of the greater below-ground foraging abilities of feral swine compared to nontarget animals in southern Texas. During trial 2 we found cumulative removal rates for surface-deployed baits to be between $68 \%$ and $75 \%$, whereas buried baits showed cumulative removal rates between $60 \%$ and $72 \%$. These findings and lack of differences in removal rates by feral swine, or any species, among surface-deployed and buried baits were in opposition to our hypothesis. Buried baits have been used extensively in Australia to increase bait specificity to carnivores (e.g., see Allen et al. 1989, Thomson and Kok 2002, Glen and Dickman 2003). However, this laborintensive mode of deployment did not increase the overall feral swine removal rate in our study in southern Texas.

\section{Management Implications}

Presently, our efforts to identify a swine-specific oral delivery system for pharmaceuticals in southern Texas has determined that 1) fish- and vegetable-flavored PIGOUT baits are attractive to feral swine and to other mammalian wildlife, 2) a commercially available capsaicin-based repellent does not increase swine-specific characteristics of fishand vegetable-flavored PIGOUT baits (Campbell and Long 2007), 3) deploying fish-flavored PIGOUT baits in a cluster arrangement ( 8 baits within $5 \mathrm{~m}^{2}$ ) increases removal rates by feral swine (Campbell and Long 2007), and 4) strawberry- flavored PIGOUT baits, fish- and vegetable-flavored PIGOUT baits with FeralMone, and buried fish- and vegetable-flavored PIGOUT baits are not specific to feral swine. As such, we question whether a swine-specific oral delivery system exists for this region, with its diverse assemblage of opportunistic carnivores, omnivores, and herbivores. Given the high removal by feral swine, we recommend that additional research be conducted into whether PIGOUT baits are a cost-effective bait for feral swine trapping exercises (both corral and cage traps). Additionally, given the worldwide scope of conflicts that humans experience with feral swine, we recommend that investigations involving PIGOUT baits and baits from other manufacturers take place in different regions of the United States and abroad.

\section{Acknowledgments}

We thank King Ranch Incorporated, associated lessees, and the Welder Wildlife Refuge for providing access to conduct research. We are grateful to K. Kubala and S. Rabe for assistance with digital image analysis. Financial support was provided by the United States Department of Agriculture, Animal and Plant Health Inspection Service, Wildlife Services, National Wildlife Research Center. We appreciate logistical support provided by the Caesar Kleberg Wildlife Research Institute at Texas A\&M University-Kingsville. Our mention of commercial products herein is for identification purposes and does not constitute endorsement or censure by the United States Department of Agriculture.

\section{LITERATURE CITED}

Adams, C. E., K. J. Lindsey, and S. J. Ash. 2006. Urban wildlife management. Taylor and Francis, Boca Raton, Florida, USA.

Allen, L. R., P. J. S. Fleming, J. A. Thompson, and K. Strong. 1989. Effect of presentation on the attractiveness and palatability to wild dogs and other wildlife of 2 unpoisoned wild-dog bait types. Australian Wildlife Research 16:593-598.

Bullard, R. W., S. A. Shumake, D. A. Campbell, and F. J. Turkowski. 1978. Preparation and evaluation of a synthetic fermented egg coyote attractant and deer repellent. Journal of Agricultural Food Chemistry 26: 160-163.

Campbell, T. A., S. J. Lapidge, and D. B. Long. 2006. Using baits to 
deliver pharmaceuticals to feral swine in southern Texas. Wildlife Society Bulletin 34:1184-1189.

Campbell, T. A., and D. B. Long. 2007. Species-specific visitation and removal of baits for delivery of pharmaceuticals to feral swine. Journal of Wildlife Diseases 43:485-491.

Campbell, T. A., and D. B. Long. 2008. Mammalian visitation to candidate feral swine attractants. Journal of Wildlife Management 72:305-309.

Conover, M. 2002. Resolving human-wildlife conflicts: the science of wildlife damage management. Lewis, Boca Raton, Florida, USA.

Cowled, B. D., E. Gifford, M. Smith, L. Staples, and S. J. Lapidge. 2006a. Efficacy of manufactured PIGOUT ${ }^{\circledR}$ baits for localized control of feral pigs in the semi-arid Queensland rangelands. Wildlife Research 33:427437.

Cowled, B. D., S. J. Lapidge, M. Smith, and L. Staples. $2006 b$. Attractiveness of a novel omnivore bait, PIGOUT ${ }^{\circledR}$, to feral pigs (Sus scrofa) and assessment of risks of bait uptake by non-target species. Wildlife Research 33:651-660.

Dickson, J. G., J. J. Mayer, and J. D. Dickson. 2001. Wild hogs. Pages 191208 in J. G. Dickson, editor. Wildlife of southern forests: habitat and management. Hancock House, Blaine, Washington, USA.

Dowdy, S., and S. Wearden. 1991. Statistics for research. John Wiley and Sons, New York, New York, USA.

Fletcher, W. O., T. E. Creekmore, M. S. Smith, and V. F. Nettles. 1990. A field trial to determine the feasibility of delivering oral vaccines to wild swine. Journal of Wildlife Diseases 26:502-510.

Frederick, J. M. 1998. Overview of wild pig damage in California. Proceedings of the Vertebrate Pest Conference 18:82-86.

Glen, A. S., and C. R. Dickman. 2003. Effects of bait-station design on the uptake of baits by non-target animals during control programmes for foxes and wild dogs. Wildlife Research 30:147-149.
Hunt, R. J., D. J. Dall, and S. J. Lapidge. 2007. Effect of synthetic lure on site visitation and bait uptake by foxes (Vulpes vulpes) and wild dogs (Canis lupus dingo, Canis lupus familiaris). Wildlife Research 34:461-466.

Kavanaugh, D. M., and S. B. Linhart. 2000. A modified bait for oral delivery of biological agents to raccoons and feral swine. Journal of Wildlife Diseases 36:86-91.

National Climatic Data Center. 2008. Palmer Drought Index, October 2007 to September 2008. <http://www.ncdc.noaa.gov/oa/climate/ research/prelim/drought/pdiimage.html>. Accessed 3 Nov 2008.

Palmer, W. C. 1968. Keeping track of crop moisture conditions, nationwide: the new crop moisture index. Weatherwise 21:156-161.

Seward, N. W., K. C. VerCauteren, G. W. Witmer, and R. M. Engeman. 2004. Feral swine impacts on agriculture and the environment. Sheep and Goat Research Journal 19:34-40.

Simberloff, D. 2003. How much information on population biology is needed to manage introduced species? Conservation Biology 17:83-92.

Sweeney, J. R., J. M. Sweeney, and S. W. Sweeney. 2003. Feral hog Sus scrofa. Pages 1164-1179 in G. A. Feldhamer, B. C. Thompson, and J. A. Chapman, editors. Wild mammals of North America: biology, management, and conservation. Second edition. John Hopkins University Press, Baltimore, Maryland, USA.

Thomson, P. C., and N. E. Kok. 2002. The fate of dried meat baits laid for fox control: the effects of bait presentation on take by foxes and nontarget species, and on caching by foxes. Wildlife Research 29:371-377.

Waithman, J. D., R. A. Sweitzer, D. Van Vuren, J. D. Drew, A. J. Brinkhaus, I. A. Gardner, and W. M. Boyce. 1999. Range expansion, population sizes, and management of wild pigs in California. Journal of Wildlife Management 63:298-308.

Associate Editor: Mason. 